DOI 10.37882/2223-2982.2020.04.02

\title{
ПРОТИВОРЕЧИЯ МЕЖДУ ИДЕЙНЫМИ НАПРАВЛЕНИЯМИ ОРГАНИЦИЗМА В КОНТЕКСТЕ СИСТЕМЫ ОРГАНИЧЕСКОГО МИРОВОЗЗРЕНИЯ
}

\section{CONTRADICTIONS BETWEEN THE MAIN APPROACHES OF ORGANICISM IN THE CONTEXT OF THE ORGANIC OUTLOOK}

\section{Antyushev}

Summary: Basic theoretical and methodological settings of the organicism looks like an important part of the development of modern scientific concepts (cybernetics, synergetics and system approach). It is proved that the main settings from the organicism correlate with the outlook which is based on the multidiscipline concepts of modern science. There are two parts of organic theory - classical Russian organicism and organic school in sociology. When researchers tried to figure out theoretical and methodological settings of organicism, they have to choose one of these approaches and deny other. It is necessary to make a comprehensive analysis these approaches. Only then organic outlook creates a holistic picture of the world.

Keywords: organicism, organic outlook, organic wholeness, synergistic integrity, dialectic.

\author{
Антюшев Иван Игоревич \\ Аспирант, ФГБОУ ВО «Чувашский государственный \\ педагогический университет им. И.Я. Яковлева» \\ ivan_antyushev@inbox.ru
}

Аннотация: Базовые теоретико-методологические установки концепции органицизма оказали значительное влияние на развитие современных научных теорий - кибернетики, синергетики, системного подхода. Исходные принципы органицизма, определяющие структуру органического мировоззрения, сообразны установкам, на которых базируются вышеназванные теории. Органическая концепция включает два направления: классический российский органицизм и органическую школу в социологии. Определяя теоретико-методологическое содержание и изучая генезис органицизма, исследователи склонны брать за основу одно из данных направлений, при этом принципиально отрицая роль другого. Чтобы разрешить противоречия, необходимо провести комплексный анализ обозначенных направлений, что позволит отразить целостную систему органического мировоззрения.

Ключевые слова: органицизм, органическое мировоззрение, органическое целое, синергийная целостность, диалектика.
B современной науке отчетливо прослеживается тенденция формирования междисциплинарных отраслей, при этом заметно размываются границы между социально-гуманитарным и естественнонаучным знанием. Научные парадигмы, такие как синергетика и кибернетика, стремятся рассмотреть многомерный мир как целое, разветвленную самоорганизующуюся систему. В силу данных тенденций актуализируются научные концепции, в основу которых заложен диалектический подход. Органицизм - одна из таких концепций. Принципы и идейные установки, составляющие концептуальное ядро органицизма, заложены в основу многих научных отраслей, рассматривающих мир как глобальную, целостную систему, наделенную способностью к самоорганизации.

Разработка теоретических и методологических положений органицизма ведется философами с первой половины XIX века. Органическая теория включает два основных направления: классический российский органицизм и органическую школу в социологии. Если мы обратимся к осмыслению генезиса органицизма современными исследователями, то натолкнемся на проблему, связанную с тем, что каждый из них выбирает какое-либо из двух указанных направлений и утверждает, что именно оно является теоретико-методологической основой органицизма, при этом роль второго направления в становлении органицизма отрицается в принципе. На наш взгляд, подобный подход неприемлем, поскольку он противоречит идейному содержанию органицизма, согласно которому любой объект - это целостная система, рассматриваемая с позиций диалектики, самостоятельное органическое целое. Органическое целое - это универсальный концепт, позволяющий рассматривать любую систему, учитывая при этом ее внутренние противоречия между преобразующей деятельностью и стремлением к упорядоченности. Поэтому необходимо рассматривать генезис органицизма в синтезе данных направлений, лишь тогда мы сможем всесторонне осмыслить теоретико-методологический потенциал рассматриваемой концепции.

Классический российский органицизм формируется в начале XIX века, связано это, прежде всего, с проникновением в российскую философскую мысль идей, ранее высказанных Шеллингом. Механицизм в то время начал исчерпывать свой концептуальный потенциал, в противовес ему формируется мировоззрение, ядром которого выступает диалектический подход. Так, один из родоначальников органицизма Д.М. Велланский отмечал, что 
динамичность и внутренняя противоречивость являются главными детерминантами существования любой целостной системы. Система перманентно пребывает в состоянии движения, посредством которого «происходят и действуют все вещи в природе, и по которому каждое действие должно быть полярным» [Велланский 1831, 8]. Велланский, рассматривая мир единого целого (всеобщего универсума), выдвинул один из основных принципов органицизма - принцип всеобщности жизни. В его представлении, каждый организм в структуре мироздания идентичен природе в целом: «высшие организмы суть только дальнейшее развитие низших, восходящих до совершеннейшего организма, который равен общему содержанию всех предыдущих» [Велланский 1831, 46]. Следовательно, единство объективного и субъективного факторов достигается в их взаимообусловленности.

Каким образом проявляется органический принцип всеобщности жизни? Всеобщность жизни - основная закономерность, детерминирующая бытие органического целого. А.И. Галич осмысливал ее как «изящное, имеющее цель само в себе» [Галич 1825, 20]. Спонтанные проявления изящного имеют место в свободных творческих актах человека, определяющих функционирование, жизнедеятельность и развитие органического целого. Человек, творя нечто совершенно новое, неосознанно черпает идеи из проявлений всеобщей жизненной закономерности.

Попытки нахождения модуса всеобщности жизни предпринимались также в московском «Обществе любомудрия». Например, Д.В. Веневитинов рассматривает органическое целое как «абсолютный организм, объединенный идеей мира» [Веневитинов 1934, 258]. По его мнению, всеобщность жизни - это существующее в сознании человека представление о единстве и целостности мира, сопряженное с неизменной включенностью человека в глобальный процесс жизнедеятельности органического целого. Идея мира выражена в самопознании человека, которое стимулирует изменение состояния глобальной органической системы мира. Веневитинов считает, что человек сможет построить идеальный мир лишь в том случае, если сможет уравновесить процесс самопознания нравственностью и гармонией с природой. Он утверждает, что «нравственная свобода будет общим уделом, все познания человека сольются в одну идею о человеке, все отрасли наук сольются в одну науку самопознания» [Веневитинов 1934, 136].

Всеобщность жизни в представлении В.Ф. Одоевского «обусловлена слиянием нескольких стихий, действующих с определенной целью» [Одоевский 1975, 177]. Стихии хаотичны, а их спонтанность порождает упорядоченность органического целого. Одоевский отражает данную тенденцию в своем концепте «Безуслов», являющимся в своем роде первичной установкой, универсальной закономерностью, детерминирующей целост- ность органической системы. Кроме того, Одоевский значительное внимание уделил проецированию органической теории на социальные процессы. Он рассматривает страны и народы как отдельно взятые организмы, в тесном взаимодействии которых устанавливается направление развития общества, взятого в качестве глобального органического целого. Коммуникация народов и взаимопроникновение культур им интерпретируется как некая химическая реакция. Он проводит аналогию между сознанием человека и «Безусловом», утверждая, что действуют они по идентичному алгоритму.

Движение органического целого направлено на достижение системной упорядоченности. В любой органической системе движение ее структурных компонентов представляет собой непрерывный, но, в то же время, цикличный процесс. Человек, в силу присущей ему способности проектировать и направлять свои действия, ускоряет самоорганизацию внутри органической системы. Цикличность развития органического целого, по мнению М.Г. Павлова, проявляется в «смене процессов возникновения и уничтожения, олицетворяющих собой дыхание Вселенной» [Павлов 1833, 168]. Руководством циклами занимаются две противоположные по своей сущности силы - расширительная и сжимающая. Посредством их сдержек и противовесов органическое целое сохраняет свою структуру.

В теоретической базе классического российского органицизма важное место занимает принцип целостности, отражающий структуру органического целого. Н.О. Лосский охарактеризовал структуру органической системы следующим образом: «каждая часть существует для целого, целое существует для каждой части, каждая часть и есть целое» [Лосский 1991, 405]. Важно отметить, что органическое целое больше, нежели просто сумма всех его составных частей. Таким образом, в любой органической системе имеет место системный эффект, или эмерджентность, а мир в контексте органического мировоззрения - это синергийное целое.

Идеи, высказанные представителями первого направления, сформировали теоретическую базу органической теории, вывели органицизм на метауровень. Однако методологическая часть данной концепции, на наш взгляд, интенсивнее разрабатывалась в рамках второго направления - органической школы в социологии, получившей свое наибольшее развитие во второй половине XIX века.

Органическая школа в социологии параллельно развивалась как российскими (А.И. Стронин, П.Ф. Лилиенфельд), так и зарубежными философами (Г. Спенсер, А. Шеффле, Р. Вормс). Отметим, что значительное влияние на развитие идей данного направления оказало формирование позитивизма, позволившее обозначить социологию как самостоятельную науку. В основу социологии 
заложены рассмотренные нами выше идеи органицизма, что отчетливо прослеживается в ее определении, которое привел О. Конт. По его мнению, социология это наука, главную цель которой составляет «изучение социальных явлений, рассматриваемых в том же духе, как и явления астрономические, физические, химические и физиологические, то есть как подчиненные неизменным естественным законам, открытие которых составляет специальную цель их исследований» [Лапин $2003,26]$. Естественные законы здесь рассматриваются как отражение «идеи всеобщего согласия» [Конт 2012, 122]. Человечество, как и любая система, действует по закономерностям, установленным данной идеей. Конт определяет общество как некое «великое существо, которое состоит из отдельных элементов, а все его существование покоится на взаимной любви, связывающей постоянно его различные части, причем никакой расчет никогда не мог бы заменить этого инстинктивного чувства» [Конт 2012, 149]. Таким образом, Конт продолжил мысль своего учителя А. Сен-Симона, ранее утверждавшего, что все люди представляют собой организованные тела, поэтому постичь закономерности развития социума можно лишь тогда, когда мы будем «рассматривать наши общественные отношения как явления физиологические» [Сен-Симон 1948, 130]. Следовательно, благодаря позитивистам органическая теория преодолевает умозрительный характер, проецируясь на систему социальных взаимодействий.

Приверженцы идей органической школы в социологии проводили аналогии между биологическими и социальными системами, за что неоднократно подвергались критике. Например, Г. Спенсер утверждал, что общество представляет собой единый живой организм (социальный организм). Общество, как и любой биологический организм, «неизменно растет, его части становятся несходными между собою, оно обнаруживает усложнение строения» [Спенсер 1997, 287]. Кроме того, процесс роста органического целого неизменно сопряжен с «взаимной дифференциацией социального строения и социальных процессов». Именно социальные процессы, перманентно зависимые друг от друга, детерминируют развитие общества в целом. Однако прямые аналогии вовсе не ставят цель отождествить биологические и социальные системы. Их строение хоть и подчиняется одним и тем же закономерностям, но оно вовсе не идентично. Биологический организм, в отличие от социальной системы, дискретен. Социум не является стандартизированным набором объектов, образующих единое целое. В любом живом организме его структурные элементы тесно взаимодействуют друг с другом, тогда как в обществе коммуникация может происходить спонтанно или опосредованно. Кроме того, данный процесс осуществляется посредством эмоциональной и интеллектуальной активности субъектов, что детерминируется разумом. Этот момент проводит еще одну черту сходства органической целостности с живой материей. Однако со- знание в данных организмах распределяется несходно: в любом живом организме сознание сконцентрировано в определенной области, в то время как в социальном организме оно распространяется повсеместно на каждый отдельный его элемент, иными словами, «все единицы этого агрегата обладают приблизительно равной способностью ощущать счастье и несчастье» [Спенсер 1997, 288]. Приводя подобные аргументы, Г. Спенсер указывал на то, что социальная эволюция - это неотъемлемая часть эволюции универсума. Органическое целое в его представлении - это обширная система, характеризующаяся высокой степенью взаимного влияния ее структурных элементов друг на друга. Она состоит из множества подсистем (внутренней, внешней, распределительной), действующих в неразрывной связке.

Значительное внимание социологи органической школы уделяли обоснованию решающей роли эволюционных процессов в развитии органического целого, что связано с популяризацией в тот период эволюционной теории Ч. Дарвина. Именно тогда начинает формироваться концепция глобального эволюционизма, столь актуальная и в современной науке. Органицизм впитал в себя эволюционные идеи, экстраполировав их на общественную модель. Например, А. Шеффле указывал на то, что естественный отбор - это наиболее объективная закономерность развития социума. Конкурентная борьба в обществе происходит посредством идейно-мировоззренческих противоречий, детерминирующих самосознание и поведенческие установки человека. Духовная сфера общества формируется как закономерный результат естественного отбора. Отметим, что А. Шеффле также не скупился на аналогии между биологическим и социальным организмом, поэтому духовная сфера общества для него идентична нервной системе, которая пронизывает тело и диктует мотивы совершаемых действий. Идеи, высказанные А. Шеффле, подготовили почву для осуществления прямых аналогий между живым организмом и обществом. Они коррелировали с мыслями, высказываемыми российскими коллегами А. Шеффле, несмотря на то, что сами философы никогда не взаимодействовали напрямую. В российской органической школе пошли дальше, развив биосоциальные теории посредством рассмотрения органического целого как живого организма, развивающиеся в пространстве и времени не только идеально, но и реально.

Представители российской органической школы в социологии, называвшие себя «органиками», всецело противопоставляли свои взгляды механистической картине мира. Согласно их точке зрения, социальные процессы детерминируются теми же закономерностями, что и природные явления. Органическое целое - это существующий в реальности живой организм. Данный факт они подтверждают доказательством идентичности структурных алгоритмов на микроуровне. Так, А.И. Стронин в качестве доказательства приводит тезис, указыва- 
ющий на то, что «отторжение отдельно взятого органа в теле человека приводит к тем же последствиям, то и отторжение территории у государства» [Стронин 1885, 192]. В его концепции социальная структура наделяется свойствами живой материи, в ней существует главный орган, без которого невозможно адекватное функционирование всего органического целого. Именно поиски подобного органа, удерживающего структуру целостности, в его реальном воплощении и стали основой научных изысканий представителей органической школы. Они пытались доказать реальность существования некой доминанты, с помощью которой можно было бы перманентно сохранять целостность глобальной системы

Не стоит воспринимать прямые аналогии в буквальном смысле. Цель социологов-органиков заключалась в прослеживании единства структурных закономерностей, в доказательстве универсальности системной организации. Например, П.Ф. Лилиенфельд-Тоаль указывает, что реальность социального бытия детерминируется отнюдь не взаимным наружным сходством с живым организмом, а «единством происхождения, строения и функционирования всех организмов» [Лилиенфельд-Тоаль $2012,161]$. Пытаясь преодолеть абстрактность аналогии, он утверждает, что духовные силы человека визуализируется в структуре органического целого посредством социальных явлений, которые рассматриваются в качестве коммуникатора, системы причинно-следственных связей между элементами общества. Рассматривая социальную систему как реальный организм, не стоит сравнивать ее исходные характеристики в контексте любого отдельно взятого биологического организма. В организме человека имеют место сознание и разум, проявляющиеся как результат деятельности мозга, животные же действуют инстинктивно. Органическое целое - это упорядоченная совокупность людей, соответственно не следует его сопоставлять с организмами животных.

Кроме того, П.Ф. Лилиенфельд-Тоаль дополняет свои аналогии, выходя на уровень гомологии, представляющей собой «глубинное, внутреннее сходство, восходящее к генезису» [Лилиенфельд-Тоаль 2012, 36]. Только при совместном применении методов аналогии и гомологии представляется возможным проследить структурно-функциональное единство живых организмов.

В своей концепции П.Ф. Лилиенфельд-Тоаль также затронул проблему определения закономерностей девиаций органического целого, сформулировал представление о социальной патологии и обосновал методологию ее преодоления - социальную терапию. По его мнению, органическое целое будет прогрессивно развиваться в том случае, если в его структуре «осуществляется гармоническая взаимосвязь всех функций в соотнесенности с их целевым назначением» [Лилиенфельд-Тоаль 2012, 105]. Если же действия составных элементов нецелесообразны жизнедеятельности органического целого, в его структуре начинает развиваться социальная патология. Отметим, что он разграничивает понятия девиации (отклонения) и социальной патологии. В его интерпретации под девиацией (отклонением) понимаются спонтанные отклонения от нормы на уровне отдельных компонентов органического целого, тогда как социальная патология - это отклонение, вызывающее разложение целостной системы. Отклоняющиеся тенденции в социальной системе не всегда наделяются исключительно негативной окраской. Например, трансгрессия, выраженная в спонтанности творческих актов человека, может способствовать прогрессивному изменению структуры универсума. Девиация - это неотъемлемая часть жизни разветвленной целостности, тогда как патология представляется явлением, резко диссонирующим с жизненным процессом. Патологические тенденции пронизывают структуру системного образования насквозь, это «крайнее проявление заболевания, выраженное в отклонении от социального типа общества» [Кузьмина 2007, 101].

Законы общественного развития определяют жизнедеятельность органического целого, пренебрежение ими вызывает неизбежное развитие социальной патологии. П.Ф. Лилиенфельд-Тоаль отмечает, что «если в органической природе болезнь может охватывать физиологическую, морфологическую или индивидуальную сторону, так и в обществе может приходить в расстройство экономическая, юридическая или политическая сфера социального развития» [Лилиенфельд-Тоаль 2012, 107]. Любое органическое тело может быть подвержено определенным заболеваниям, которые проявляются как реакция на неблагоприятные условия жизни. Данный процесс имеет место в том случае, когда «приспособляющие организм к среде способности не в состоянии без нарушений содействовать различным жизненным процессам» [Лилиенфельд-Тоаль 2012, 101].

Кроме того, П.Ф. Лилиенфельд-Тоаль при построении своей концепции оперировал реально-генетическим методом, с помощью которого он смог рассматривать жизнь не как отдельное изолированное и функциональное явление, а как явление планетарное и космическое, исторически закономерное. Эта тенденция в дальнейшем получила развитие в работах В.И. Вернадского, который исходил из идеи единства научного знания и взаимосвязи различных форм движения материи (неорганической, органической и социальной).

Идеи П.Ф. Лилиенфельда-Тоаля нашли свое продолжение в трудах Р. Вормса, определявшего общество как «прочное соединение живых организмов, проявляющих свою деятельность сообща» [Вормс 1997, 16]. Организм в его трактовке представляет собой единую целостность, «живое, состоящее из живых частей» [Вормс 1997, 7]. Согласно его точке зрения, жизнь находит свое проявление лишь в организмах, в иных формах она вопло- 
щаться не может. Организм, в свою очередь, наделен тенденцией к постоянному движению, как внешнему, так и внутреннему. В представлении Р. Вормса организм есть система открытого типа, склонная к перманентному обмену энергией не только с другими системами, но и между своими составными элементами. Органическая целостность поддерживается за счет взаимозависимых противоборствующих внутренних сил. Иными словами, упорядоченность и иерархичность органической структуры достигается посредством диалектичной связи ее составных компонентов. С помощью прямой аналогии P. Вормс указывает на общность структурных закономерностей биологических и социальных организмов. Он пытается показать, что для всех воспринимаемых человеком объектов реальности допустимо восприятие в рамках единой структуры - целостной системы, наилучшим примером которой нам представляется организм.

Таким образом, органическая школа в социологии является закономерным этапом в процессе формирования теоретико-методологической основы органицизма. Если представители классического российского органицизма стремились разработать теоретическое обоснование органического мировоззрения в противовес механицизму, то социологи органической школы своими аналогиями пытались оправдать данное обоснование, отражая органическое мировоззрение через призму социальных процессов. Поэтому, на наш взгляд, неверно отторгать влияние социологов органической школы на становление органицизма как самостоятельной, универсальной теоретико-методологической концепции. Аналогии биологических и социальных процессов, возможно, кажутся тривиальными в контексте органического мировоззрения, однако они необходимы в целях конкретизации методологической основы органицизма.

Таким образом, органическое мировоззрение - это универсальный способ познания мира, позволяющий провести системный анализ процессов в структуре реальности через призму идеи о синергийной целостности воспринимаемых объектов. Оно обладает значительными перспективами в преодолении дискретности научного познания в структуре современной науки, является своеобразным генератором идей, концепций и теорий, стремящихся синтезировать разрозненные части научного знания в единую систему. Кроме того, оно всесторонне способствует созданию целостной картины мира, что приближает человека к познанию универсальных закономерностей бытия.

Рассмотренные выше направления сформировали теоретико-методологическую основу органицизма. Именно поэтому, приуменьшая значимость какого-либо из них, мы рискуем сузить сферу применения органицизма, снизить объективность осмысления рассматриваемых через его призму процессов и явлений. Философы и социологи утвердили главные закономерности развития универсума, подробно исследовали его сущность, установили связь между его структурными элементами. Благодаря их разработкам, органицизм оформился как самостоятельная теоретико-методологическая концепция, а его идейное содержание оказало значительное влияние на формирование и развитие многих теорий, актуальных в современной науке.

\section{ЛИТЕРАТУРА}

1. Велланский Д.М. Опытная, наблюдательная и умозрительная физика. СПб., 1831. С.8.

2. Веневитинов Д.В. Полное собрание сочинений. М.-Л.: изд-во АСАDEMIA, 1934. С.258.

3. Вормс Р. Общественный организм; пер. с фр. А.С. Трачевского. СПб.: Издание Ф. Павленкова, 1997. С.16.

4. Галич А.И. Опыт науки изящного. СПб., 1825. С.20.

5. Конт 0. Общий обзор позитивизма; пер. с франц. под ред. Э.Л. Радлова. Изд. 3-е. М.: Книжный дом «ЛИБРОКОМ», 2012. С.122.

6. узьмина Г.П. Органическая теория общества о «болезнях» социального организма // Философия и общество. 2007. № 1. С.101.

7. Лапин Н.И. Когда и как Огюст Конт ввел термин «sociologie» // Социологические исследования. 2003. №4. С.26.

8. Лилиенфельд-Тоаль П.Ф. Мысли о социальной науке будущего: Человеческое общество как реальный организм. 2-е изд. М.: Книжный дом «ЛИБРОКОМ», 2012. C.101.

9. Лосский Н.О. Избранное. М.: Правда, 1991. С.405.

10. Одоевский В.Ф. Русские ночи. Л.: Наука, 1975. С.177.

11. Павлов М.Г. Основания физики. М.: Типография Степанова, 1833. С. 168

12. Сен-Симон А. Избранные сочинения. Т. 1; пер. с франц. под ред. Л.С. Цетлина. М.-Л.: Издательство Академии наук СССР, 1948. С.130.

13. Спенсер Г. Синтетическая философия; пер. с англ. П.В. Мокиевского; под ред. С.Д. Кошиса. Киев: Ника-Центр, 1997. С.287.

14. Стронин А.И. История общественности. СПб.: Типография Министерства путей сообщения (Ф. Бенке), 1885. С.192. 